\title{
ON THE ATTENUATION OF A WAVE PACKET IN LIMITED SYSTEMS FILLED WITH AN ACTIVE MEDIUM AND PLASMA
}

\author{
(D)Volodymyr M. Kuklin*, (D)Eugen V. Poklonskiy, (D)Sergey M. Sevidov \\ V.N. Karazin Kharkiv National University, Kharkiv, Ukraine \\ Svobody Sq. 4, Kharkiv, Ukraine, 61022 \\ *Corresponding Author: kuklinvm1@gmail.com \\ Received January 20, 2020; revised January 28, 2020; accepted January 30, 2020
} In the article, for limited system conditions that form the spatial structure of the field, the attenuation processes of wave packets of
finite amplitude are considered. The line width of the wave field may be the result of the dissipative processes (in a quantum system it
is inverse of the lifetime of energy levels) or the result of reactive processes (in classical waveguide systems this is the spectral width
of the packet). In the case of filling the waveguide with an active two-level medium, a description is possible using a quasiclassical
model of the interaction of the field and particles. In this case, the quantum-mechanical description of the medium is combined with
the classical representation of the field. Here, the Rabi frequency plays an important role, which determines the probabilities of induced
radiation or absorption of field quanta and the oscillatory change in population inversion (nutation). Depending on the relationship
between the Rabi frequency and the line width of the wave packet, the process can change the nature of the field behavior. In strong
fields or with a significant population inversion, the line width can be neglected, while the field energy density is quite high. In this
case, one should expect noticeable nutations of population inversions with different frequencies corresponding to the local Rabi
frequency in different regions of the waveguide, the interference of which will determine the oscillatory behavior of the wave field. At
a low level of electric field intensity or a slight population inversion, the mode of changing the field amplitude becomes monotonic.
Plasma field damping (Landau damping) is considered. The role of population inversion is assumed by a quantity proportional to the
derivative with respect to velocity of the electron distribution function. If the spectral width of the packet is small, the process of wave
attenuation acquires a characteristic oscillatory form due to the exchange of energy between the wave and the plasma electrons captured
by its field. The attenuation of wide packets is almost monotonic with the formation of a characteristic "plateau" in the vicinity of the
phase velocity of the wave on the electron velocity distribution function.

KEYWORDS: attenuation of a wave pacadge, two-level active medium, interference of oscillations of population inversion, Landau damping

Let us consider the attenuation processes of wave packets of finite amplitude in bounded systems that impose a possible set of mode wavelengths in such a package and form the spatial field structure in the waveguides. If the waveguide is filled with an active two-level medium (a system of dipoles), a description is possible using a quasiclassical model of the interaction of the field and particles (see, for example, [1]). In this case, the quantum-mechanical description of the medium is combined with the classical representation of the field. In this approach, the Rabi frequency plays an important role, which determines the probabilities of induced radiation or absorption of field quanta [2,3] and the oscillatory change in population inversion (nutation).

Depending on the relationship between the Rabi frequency $\Omega=\left|d_{a b} \| E(t)\right| / \hbar$ (where $d_{a b}$ the dipole moment of the particle and $E$ the amplitude of the electric field, respectively) and $\gamma_{12}$ the line width of the wave packet, the process can change the nature of the field behavior. Here, the line width is inversely proportional to the lifetime of states (the lifetime of energy levels), which is due to relaxation processes.

The population inversion $\mu=\rho_{a}-\rho_{b}$ (where $\rho_{a}, \rho_{b}$ are the numbers of particles at the upper and lower energy levels, respectively) is related to the energy conservation law with the number of field quanta $N=|E(t)|^{2} / 4 \pi \hbar \omega \approx \mu=\rho_{a}-\rho_{b}$. In strong fields or with a significant population inversion the line width can be neglected, while the field energy density is quite high $\gamma_{12}<\Omega=\left|d_{a b} \| E(t)\right| / \hbar$ (similar ratio can be given for population inversion $\left.\mu \gg \gamma_{12}^{2} \cdot \hbar /\left(\omega\left|d_{a b}\right|^{2}\right)\right)$. In this case, one should expect noticeable nutations of population inversions with different frequencies corresponding to the local Rabi frequency $\Omega$ in different regions of the waveguide, the interference of which determines the behavior of the wave field [4].

If the opposite inequality holds $\gamma_{12}>\Omega$, this case corresponds to rather low levels of electric field intensity or small values of population inversion, which describes the behavior of a two-level system, first formulated in [5]. The mode of changing the field amplitude becomes monotonic, the characteristic time of the field change is proportional $\tau_{\gamma} \approx \gamma_{12} / \Omega^{2}$ while the population inversion tends to zero.

However, the wave field line width can be defined as dissipative processes (in a quantum system this is the reciprocal of the lifetime of energy levels) or reactive processes of wave packet formation (in classical waveguide systems this is the spectral packet width). 
When considering the field damping in a plasma (Landau damping $[6,7]$ on electrons), the role of population inversion is taken by the quantity $\mu=n_{2}-n_{1}=f\left(v_{0}+\hbar k / m\right)-f\left(v_{0}\right)=(\hbar k / m) \cdot \partial f(v) /\left.\partial v\right|_{v=v_{0}}$, where $f(v)$ is the velocity distribution function of electrons, $n_{2}, n_{1}$ is the number of electrons whose velocity is less than and greater than the wave phase velocity $[8,9]$. In this case, it is the final spectral width of the wave packet that can affect the character of the velocity distribution of particles. With a large packet width, as is known [10], one can observe the process of socalled quasilinear relaxation, which leads to the formation of a "plateau" on the particle distribution function in the velocity space. By the way, the role of the Rabi frequency here is played by the oscillation frequency of the trapped particles in the potential well of the field $\Omega_{t r}=\sqrt{e k E / m_{e}}$ (here $e, m_{e}$ is the charge and mass of the electron, and $k$ is the wave number of oscillations, $v_{p h}=\omega / k$ the phase velocity of the wave).

If the spectral width of the packet is small $\Delta k \cdot v_{p h} \approx \Delta \omega<<\Omega_{t r}$, the process of wave attenuation acquires a characteristic oscillatory form associated with the exchange of energy between the wave and plasma electrons captured by its field. In the case of the opposite inequality, the field attenuation is almost monotonous with the formation of a characteristic "plateau" in the vicinity of the phase velocity of the wave on the electron velocity distribution function corresponding to the state with zero population inversion, which is represented in this case $\mu=(\hbar k / m) \cdot \partial f(v) /\left.\partial v\right|_{v=v_{0}}=0$. Note that in the case of simultaneous filling of the waveguide with plasma and an active medium [11], both mechanisms of expansion of the spectral generation width should be taken into account.

And in the quantum case of field attenuation at a finite line width (finite lifetime of inverted states) and at attenuation of a wave packet of finite spectral width in the classical case, one can observe a transition from an oscillatory energy exchange between particles and a wave to a regime of monotonic change in the field amplitude, with the inversion $\left(\mu=\rho_{a}-\rho_{b}\right)$ or the value corresponding to it $\left(\mu=(\hbar k / m) \cdot \partial f(v) /\left.\partial v\right|_{v=v_{0}}\right)$ tends to zero, although the nature of these changes is different. Since the real processes of propagation of oscillations in limited systems are accompanied by the formation of wave packets, the dynamics of which have not been studied enough, their evolution should be considered in more detail.

The aim of the work is to elucidate the influence of the spectral line width of the wave packet on the wave attenuation pattern in waveguides filled with active medium and plasma.

\section{MODEL OF A RESONATOR FILLED WITH AN ACTIVE TWO-LEVEL ENVIRONMENT}

Let us discuss a one-dimensional model describing the attenuation of a wave with a finite spectral line width in limited space, filled with an active medium. Generally speaking, this process can also be considered as the transition of the nonequilibrium state of the system to a stable equilibrium state, which is accompanied by the exchange of energy between the wave and the active medium. We restrict ourselves to a two-level system. For perturbations of the electric field, polarization, and population inversion slowly varying over time, describing the excitation of electromagnetic waves in an active medium, the equations can be represented in the form [1].

$$
\begin{gathered}
\frac{\partial^{2} E}{\partial t^{2}}+\delta \frac{\partial E}{\partial t}-c^{2} \frac{\partial^{2} E}{\partial x^{2}}=-4 \pi \frac{\partial^{2} P}{\partial t^{2}} \\
\frac{\partial^{2} P}{\partial t^{2}}+\gamma_{12} \frac{\partial P}{\partial t}+\omega^{2} \cdot P=-\frac{2 \omega\left|d_{a b}\right|^{2}}{\hbar} \mu E \\
\frac{\partial \mu}{\partial t}=\frac{2}{\hbar \omega}<E \frac{\partial P}{\partial t}>
\end{gathered}
$$

moreover, the transition frequency $\omega$ between the levels corresponds to the field frequency, we neglect the relaxation of the inversion due to external reasons. We define $\delta$ - the decrement of field absorption in the medium, $d_{a b}$ - the matrix element of the dipole moment of the fixed dipoles (more precisely, its projection onto the direction of the electric field), and write the population difference per unit volume as $\mu=n \cdot\left(\rho_{a}-\rho_{b}\right)$. Here, $\rho_{a}$ and $\rho_{b}$ the relative population of levels in the absence of a field $\gamma_{12}$ is the inverse relaxation time of states, which in this case determines the width of the spectral line, $n$ is the density of the dipoles of the active medium. Fields will be represented as $E=\left[E(t) \cdot \exp \{-i \omega t\}+E^{*}(t) \cdot \exp \{i \omega t\}\right]$ and $P=\left[P(t) \cdot \exp \{-i \omega t\}+P^{*}(t) \cdot \exp \{i \omega t\}\right]$. Note that in doing so $<E^{2}>=2|E(t)|^{2}$. The number of field quanta is then equal $<E^{2}>/ 4 \pi \hbar \omega=2|E|^{2} / 4 \pi \hbar \omega=N$.

For slowly varying quantities, the equations

$$
\frac{\partial E(t)}{\partial t}+\delta \cdot E(t)=2 i \pi \omega P(t)
$$




$$
\begin{aligned}
& \frac{\partial P(t)}{\partial t}+\gamma_{12} P(t)=\frac{\left|d_{a b}\right|^{2}}{i \hbar} \mu E, \\
& \frac{\partial \mu}{\partial t}=\frac{2 i}{\hbar}\left[E(t) P^{*}(t)-E^{*}(t) P(t)\right] .
\end{aligned}
$$

From equation (6), by simple transformations we find

$$
\frac{\partial N}{\partial t}+2 \delta N=\frac{i}{\hbar} \cdot\left[P(t) E^{*}(t)-P^{*}(t) E(t)\right]
$$

where can one get the conservation law

$$
\frac{\partial N}{\partial t}+2 \delta N+\frac{\partial \mu}{2 \partial t}=0
$$

To transform the above system of equations, we can use the notation $\mu / \mu_{0}=M$, $\Omega_{0}=\left|d_{a b}\right| \cdot\left|E_{0}\right| / \hbar=\left|d_{a b}\right| \cdot\left[4 \pi \omega \mu_{0} / \hbar\right]^{1 / 2}-$ the Rabi frequency corresponding to the value of the amplitude of the electric field $\left|E_{0}\right|=\left[4 \pi \hbar \omega \mu_{0}\right]^{1 / 2}, \mathrm{E}=\frac{E(t)}{\left[4 \pi \hbar \omega \mu_{0}\right]^{1 / 2}}, \mathrm{P}=\frac{P(t)}{\left[4 \pi \hbar \omega \mu_{0}\right]^{1 / 2}} \cdot \frac{4 \pi \omega}{\Omega_{0}}, \tau=\Omega_{0} t, \Gamma_{12}=\gamma_{12} / \Omega_{0}, \Theta=\delta / \Omega_{0}$. Note that the absence of time derivatives in equations (4)-(6) is associated both with the immobility of the dipoles and with the formation of a standing wave in a limited resonator system, the shape of which does not change during the development of the process. Using these notations, we rewrite equations (4) - (6) in complex form

$$
\begin{aligned}
& \frac{\partial \mathrm{E}}{\partial \tau}+\Theta \mathrm{E}=\frac{i}{2} \mathrm{P}, \\
& \frac{\partial \mathrm{P}}{\partial \tau}+\Gamma_{12} \mathrm{P}=-i M \mathrm{E}, \\
& \frac{\partial \mathrm{M}}{\partial \tau}=-2 i\left[\mathrm{E}^{*} \mathrm{P}-\mathrm{EP}^{*}\right] .
\end{aligned}
$$

The generation cases described by equations (10) - (12), when the natural line width is much less than the Rabi frequency $\Gamma_{12}<<1$, under the conditions of the formation of a standing electromagnetic wave due to reflections from its boundaries, were considered in [4]. If the conditions $\Gamma_{12} \gg>1$ are satisfied, the oscillatory character (nutations) of the population inversions can be neglected and equations (7-9) can be written in the form

$$
\begin{aligned}
& \frac{\partial \mathrm{N}}{\partial \tau}+2 \Theta \mathrm{N}=\frac{\mathrm{N} \cdot M}{\Gamma_{12}} \\
& \frac{\partial M}{\partial \tau}=-2 \frac{\mathrm{N} \cdot M}{\Gamma_{12}} .
\end{aligned}
$$

Note that the transition from equation (7) to equation (10) is similar to the transition to the case noticeable spectral field width, when the spectral line width is greater than the inverse characteristic time of the change in the amplitude of perturbations $[12,13]$. In dimensionless variables, this condition can be written as $\Gamma_{12}>\frac{\partial \mathrm{P}}{\mathrm{P} \cdot \partial \tau}$, or something the same $\gamma_{12} \gg \Omega=\left|d_{a b} \| E(t)\right| / \hbar$. Obviously, the line width noticeably exceeds the Rabi frequency, while the characteristic time of the field change is proportional $\tau_{\gamma} \approx \gamma_{12} / \Omega^{2}$. This case corresponds to rather low levels of electric field intensity or small values of population inversion $\gamma_{12}>[4 \pi \omega]^{1 / 2}\left|d_{a b}\right| \mu / \hbar^{1 / 2}$.

That is, the system of (balanced) equations (9) - (10) describes the behavior of a two-level system in the presence of an electric field, first formulated in [5].

It should also be noted that the interval of variation of the inversion is determined by the choice $\mu_{0}$ and the initial conditions, that is, the inversion at the initial moment can be both equal $\mu(0)=\mu_{\max }=\rho_{a}$ and much smaller.

\section{ATTENUATION OF A WAVE PACKAGE IN A RESONATOR FILLED WITH AN ACTIVE MEDIUM}

In the resonator, the electromagnetic field is established due to reflection from the ends of the system partially or completely, as in the case under consideration. However, the inversion and polarization of the quantities localized in space, which allows us to determine these variables in individual spatial sectors. That is, the electromagnetic field can be represented as a standing wave, and in each of the spatial sectors $1<j<S$ the field intensity can be represented in the form 


$$
\left|\mathrm{E}_{j}(\tau=0)\right|^{2}=2 \frac{1}{S} \cdot|\mathrm{E}(\tau=0)|^{2} \cdot \operatorname{Sin}^{2}\left\{2 \pi \frac{j}{S}+\alpha\right\},
$$

where $\alpha$ is an almost constant phase associated with the absorption of field energy $\delta$. In the general case $\delta \approx \frac{c}{4 \pi}|E|^{2}(x=0) /\left(\frac{\left.<\left.E\right|^{2}\right\rangle}{4 \pi} b\right)$, where $b=m \lambda$ is the waveguide length.

It is easy to see that $|\mathrm{E}|^{2}(x=0)=<|\mathrm{E}|^{2}>\operatorname{Sin}^{2} \alpha$ and $\delta \approx c\left(\operatorname{Sin}^{2} \alpha\right) / 2 b$ where $c$ is the group velocity of the wave outside the waveguide. However, we neglect the radiation from the waveguide below $\alpha=0$. We can verify that $\sum_{j} 2 \frac{1}{S} \operatorname{Sin}^{2}\left\{2 \pi \frac{j}{S}\right\}=m$ in the case under consideration, when a countable number of waves $m$ fit along the length of the waveguide $b=m \lambda$. The total (relative) number of field quanta can be written in the form

$$
N(\tau)=2 \sum_{j=1}^{S}\left|\mathrm{E}_{j}(\tau)\right|^{2}=2|\mathrm{E}(\tau)|^{2} .
$$

It is clear that without violating generality we can consider the case $m=1$. The system of equations (7) - (9) in this case is transformed as follows.

$$
\begin{aligned}
& \frac{\partial \mathrm{P}_{j}}{\partial \tau}+\Gamma_{12} \mathrm{P}_{j}=-i M_{j} \mathrm{E}_{j}, \\
& \frac{\partial M_{j}}{\partial \tau}=2 i\left[\mathrm{E}_{j} \mathrm{P}_{j} *-\mathrm{E}_{j} * \mathrm{P}_{j}\right]
\end{aligned}
$$

where $\mathrm{E}_{j}(\tau)=\left(\sqrt{\frac{2}{S}}\right) \cdot|\mathrm{E}(\tau)| \cdot \operatorname{Sin}\left\{2 \pi \frac{j}{S}\right\}, \frac{1}{2} \sum_{j=1}^{S}\left(M_{j}+M_{j}^{*}\right)=\mathrm{M}$.

We can also write down the conservation law, a consequence of equations (7) and (9)

$$
\frac{1}{2} \frac{\partial \mathrm{M}}{\partial \tau}+\frac{\partial \mathrm{N}}{\partial \tau}=0
$$

Note that the time scale in this description is related to the scale of a simple model [4], as follows $\tau \rightarrow \tau \sqrt{S}$. A remarkable circumstance is the quality identity of the calculation results for the case of a simple model [4] and the more complicated description given below for the case of a narrow spectral line $\left(\Gamma_{12}=0\right)$, which indicates a rather simple mechanism of energy exchange between the wave and the active medium. It demonstrates the importance of interference of oscillations (nutations) population inversions to describe changes in the amplitude of the field of a steady form in a waveguide.

Results of numerical simulation. For calculations, we use equations (13)- (15), as well as the following quantities $N(\tau)=\frac{1}{S} \sum N_{j}(\tau), M(\tau)=\frac{1}{S} \sum M_{j}(\tau), \quad \mathrm{E}_{j}(\tau)=\sqrt{2 N(\tau)} \cdot \operatorname{Sin}\left(2 \pi \frac{j}{S}\right)$. Below we used the initial conditions $N_{0}=1.45, M_{0}=-1, S=100, \Theta=0$. Attention should be paid to the oscillations caused by the interference of the processes of induced radiation and absorption of field quanta in different parts of the waveguide (Fig. 1.). This phenomenon is discussed in detail in [4].

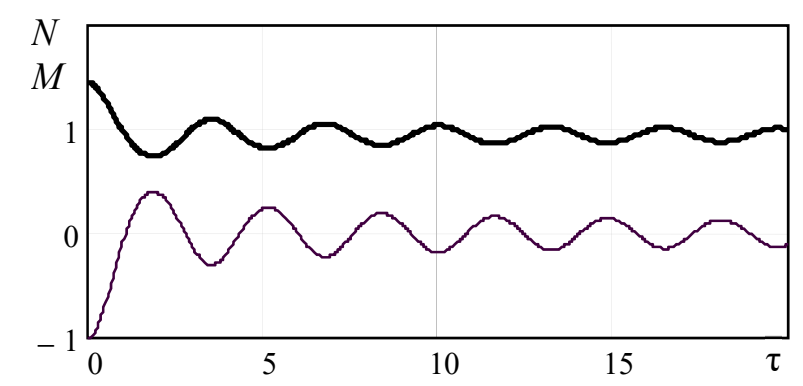

Fig. 1. The behavior of the relative number of quanta (bold line) and relative population inversion (thin line) over time with a negligible line width $\Gamma_{12}=0$.

The population inversion oscillation frequency corresponds to the Rabi frequency and is proportional to the electric field in this local region. From the equations of a simple model presented in [4] for the same initial conditions it follows $N+0.5 M=N_{0}+0.5 M_{0}=0.95$. It turns out in our case with different line widths over time $N \rightarrow 0.95$, moreover 
$M \rightarrow 0$. With an increase in the width of the oscillation line of the field intensity (the number of quanta) and population inversions weaken (Fig. 2.)

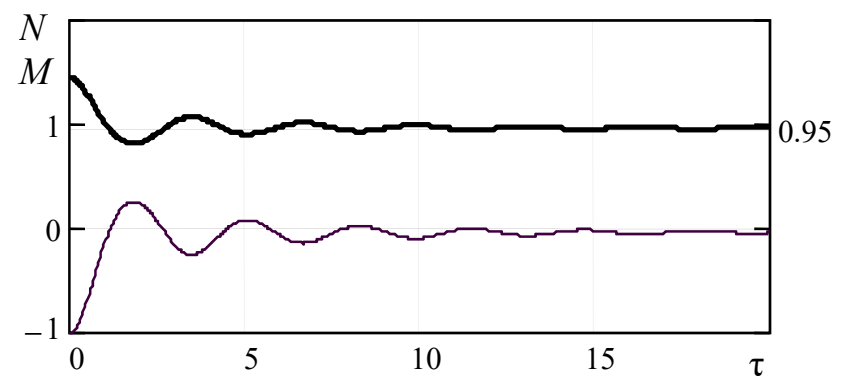

Fig. 2. The behavior of the relative number of quanta (bold line) and the relative population inversion (thin line) over time with a small line width $\Gamma_{12}=0.25$.

With a sufficiently large line width, the mode of changing the field intensity (number of quanta) and population inversion becomes monotonic (Fig. 3.)

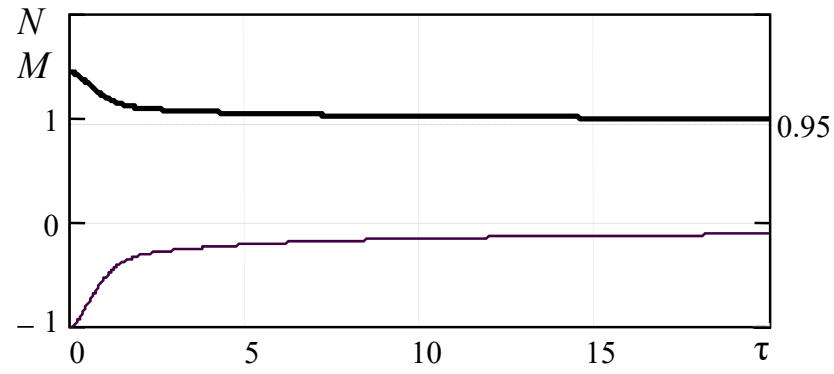

Fig. 3. The behavior of the relative number of quanta (bold line) and relative population inversion (thin line) over time with a line width $\Gamma_{12}=3$.

This behavior of the number of quanta and the population inversion of a two-level system in the presence of an electric field is characteristic of the case when the process is described by balance equations, first presented in [5]. It is important to note that the finite width of the wave packet is able to suppress the interference of population inversion sections oscillating with different local Rabi frequencies in the field of a standing wave.

In conclusion of the section, we note that the broadening of the vibrational spectrum can occur not only due to relaxation of states (i.e., changes in the number of particles at the upper and lower energy levels) of the quantum system at small (or, which is one and the same, polarization attenuation, which can be seen from the equation (16)). In the case of a long waveguide, the field in the waveguide may exist in the form of a wave packet, the spectral width of which $\Delta k \cdot c=(2 \pi / \lambda)\left[m^{-1}-(m-1)^{-1}\right]=\omega / m^{2}$. When $\omega / m^{2}>\gamma_{12}$ the dynamics of the field attenuation in the waveguide can determine the spectral width of the wave packet. We consider this case below, where the processes of changing the number of particles at the upper and lower energy levels in the absence of a field are not significant.

\section{ATTENUATION OF THE LANDAU WAVE PACKAGE IN A HOT PLASMA}

Consider the process of attenuation of plasma (Langmuir) waves on plasma electrons. Electrons effectively interact with the wave, moving at a speed close to the phase velocity of the wave packet. For simplicity, we restrict ourselves to the one-dimensional case [6] (see also [7]). In this one-dimensional representation, plasma electrons emit and absorb quanta of longitudinal (Langmuir) waves - plasmons whose energy is equal $\hbar \omega(k)$. According to $[8,9]$, we determine the number of longitudinal wave quanta emitted per unit time in the range of wave numbers $d k$ in cases of spontaneous and induced processes $n_{m} u_{m n} d k$ and $n_{m} w_{m n} N_{k} d k$, accordingly.

In this case, the particles emitting the quantum of the field - the plasmon, pass from state $m$ to state $n$. In the same wavelength range, we similarly determine the plasmon absorption rate $n_{n} w_{n m} N_{k} d k$, where $n_{m}$ is the number of particles in the state $m$, and $N_{k}$ is the number of field quanta, $u_{m n}, w_{m n}, w_{n m}$ are the coefficients in A. Einstein's equations which are equal to each other in the onedimensional case, considered below [14].

$$
\partial n_{m} / \partial t=-\left(u_{m n}+w_{m n} \cdot N_{k}\right) \cdot n_{m}+w_{n m} \cdot N_{k} \cdot n_{n},
$$




$$
\partial n_{n} / \partial t=-w_{n m} \cdot N_{k} \cdot n_{n}+\left(u_{m n}+w_{m n} \cdot N_{k}\right) \cdot n_{m} .
$$

To describe the dynamics of the number of plasmons, we obtain the equation

$$
d N_{k} / d t=u_{m n} \cdot n_{m}\left\{\left(1-n_{n} / n_{m}\right) \cdot N_{k}+1\right\} .
$$

Note that the change in the plasmon energy density $d \mathrm{E}_{k} / d t=\hbar \omega(k) \cdot u_{m n} \cdot n_{m}$ due to spontaneous emission of particles per unit time is equal $w(k)$. With this in mind, the complete equation for the plasmon energy density takes the form:

$$
d \mathrm{E}_{k} / d t=w(k) \cdot\left\{\left(1-n_{n} / n_{m}\right) \cdot N_{k}+1\right\} .
$$

The change in the momentum of the particles upon plasmon emission $m \cdot\left(v_{m}-v_{n}\right)=\hbar k$, whence it follows $v_{m}=v_{n}+\hbar \cdot k / m$, which is also the case if the velocity interval over which the particle distribution function changes significantly exceeds $\hbar k / m$

$$
\mu=n_{m}-n_{n}=f\left(v_{n}+\hbar k / m\right)-f\left(v_{n}\right)=(\hbar k / m) \cdot \partial f(v) /\left.\partial v\right|_{v=v_{n}}
$$

moreover, the value $\mu$ has the meaning of population inversion. For the spectral intensity of spontaneous emission of plasma particles $w(k)$, one can obtain the expression [9]

$$
w(k)=2 e^{2} \int_{-\infty}^{\infty} d v \cdot v \cdot f(v) \cdot \operatorname{Im}[k \varepsilon(k v, k)]^{-1}=2 \pi^{2} e^{2}\left[\omega_{p e}^{2} / k^{3}\right] \cdot f[\omega(k) / k],
$$

and equation (19) describing the spontaneous (first term of the right-hand side) and induced radiation (second term of the right-hand side) of Langmuir waves by plasma particles takes the form

$$
d \mathrm{E}_{k} / d t=2 \pi^{2} e^{2}\left[\omega^{2}(k) / k^{2}\right] \cdot\left\{f[\omega(k) / k]+\mathrm{E}_{k} \cdot(k / \omega(k) \cdot m) \cdot \partial f(v) /\left.\partial v\right|_{v=\omega(k) / k}\right\} .
$$

If the velocity distribution function has the form $f(v)=\left(n_{0} / v_{T} \sqrt{\pi}\right) \cdot \exp \left\{-\frac{v^{2}}{v_{T}^{2}}\right\}$, then the second term determines the linear decrement of the Landau damping of the Langmuir wave $\delta_{L}$ whose phase velocity $\omega / k$ is on plasma particles (we neglect spontaneous emission)

$$
d \mathrm{E}_{k} / d t=-2 \delta_{L} \mathrm{E}_{k}=\pi\left[\omega^{3}(k) / n_{0} k\right] \frac{\partial f(v)}{\partial v} \cdot \mathrm{E}_{k}=\sqrt{\pi} \frac{\omega^{3}(k v-\omega)}{k^{3} v_{T}^{3}} \exp \left\{-\frac{(v-\omega / k)^{2}}{v_{T}^{2}}\right\} \cdot \mathrm{E}_{k} .
$$

The complex equation for the field, which describes the process of induced absorption of the plasma wave field by plasma electrons, can be written as

$$
\frac{\partial(\omega \varepsilon)}{\partial \omega} \frac{\partial E_{n}}{\partial t}+i \omega \varepsilon \cdot E_{n}=\left.\frac{4 \pi e \omega}{k} \frac{\partial f}{\partial v}\right|_{0} \cdot \int_{-\pi / k}^{\pi / k} d \xi_{0} \int_{-v_{m}}^{v_{m}} v_{0} d v_{0} \exp \left(i k_{n} \xi+i \varphi_{n}\right)
$$

where $\quad \xi=x-v_{0} t, \quad \Delta v=v-v_{0}, \quad n_{b 0}=\int f_{0}(v) d v, \quad \Delta v_{m} \propto 6 \pi|\gamma| / k_{0}, \quad$ and the initial conditions $\xi_{0}=\xi(t=0) \subset\left(-\pi / k_{0}, \pi / k_{0}\right)$ and $\Delta v_{0}=\Delta v(t=0) \subset\left(-\Delta v_{m}, \Delta v_{m}\right)$.

Results of numerical simulation. For calculations we use the equations

$$
\begin{aligned}
\frac{\partial A_{n}}{\partial \tau}+i\left(n-n_{0}\right) A_{n} & =-8 \pi \int_{-0.5}^{0.5} d \xi \int_{-\eta}^{+\eta} d \eta \cdot \eta \cdot \exp \{-2 \pi n i \xi\}, \\
2 \pi \cdot \frac{\partial^{2} \xi}{\partial \tau^{2}} & =-\operatorname{Re}\left[\sum_{3}^{6} A_{n} \cdot \exp \{2 n \pi i \xi\}\right],
\end{aligned}
$$

where are the modes of the wave packet $A_{n}=\left|A_{n}\right| \exp \left\{i \varphi_{n}\right\}$, the main wave of $n_{0}=5$, the satellite $n=3 ; 4 ; 6 ; 7$, under the following initial conditions: $A_{5}=1.0$ - the amplitude of the main wave, the amplitudes of the satellites $-A_{3}=A_{7}=0.2$; $A_{4}=A_{6}=0.7$; the number of particles is $5000, \xi \subset(0,1)$ and $\eta=\frac{1}{2 \pi} \cdot \frac{d \xi}{d \tau}, \xi=\frac{k x}{2 \pi}$.

The behavior of the wave packet over time is investigated by changing the sum of squares of modules of all amplitudes $\left|A_{\mathrm{n}}\right|^{2}$. This value determines the intensity of the resulting wave of our package: $I=\sum_{n=3}^{7}\left|A_{n}\right|^{2}$. We observe the decrease of the intensity of the wave packet, associated with the energy exchange between the field and the captured wave plasma electrons (Fig. 4). 


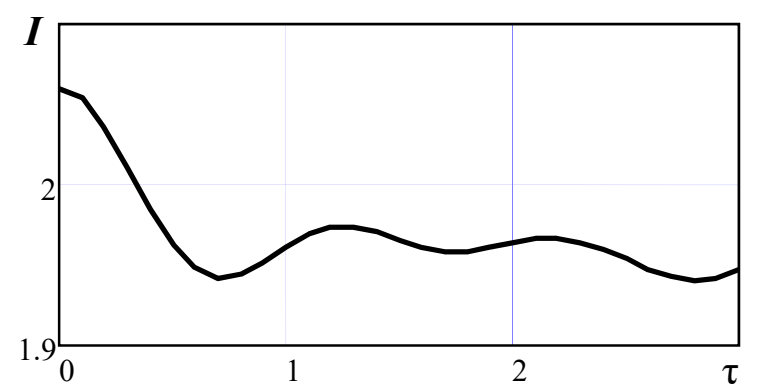

Fig. 4. The behavior of the intensity of wave $I$ over time for the wave packet

In single-mode mode (the case of a narrow line width of the wave packet) oscillation of the wave intensity is observed. This mode of wave attenuation at the initial stage is known as Landau attenuation. In the calculated scheme, the intensity of the monochromatic wave is equal to $I=\left|A_{5}\right|^{2}$. In the developed mode the process becomes nonlinear $[9,10]$ with weak fading oscillations of the field (see Fig. 5).

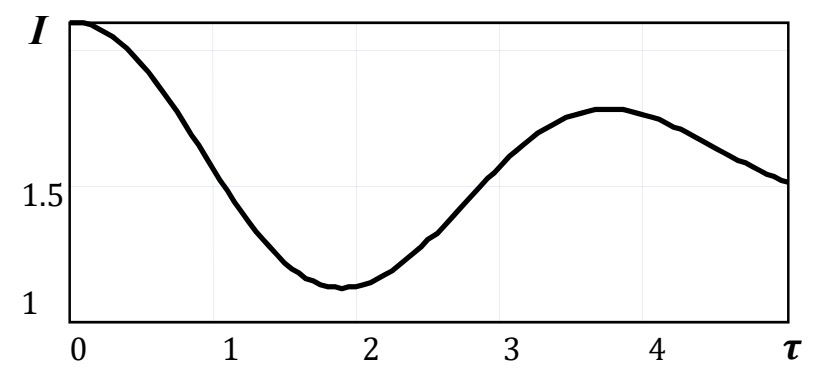

Fig. 5. The behavior over time of the intensity of wave $I$ in single mode.

The electron distribution function in the vicinity of the phase wave velocity for different time instants for wave packets with different line widths is shown in Fig. 6,7.

We can cite the change in the distribution function of plasma electrons with time. In the single-mode the distribution function has a large change in oscillations of the wave amplitude (Fig. 6)

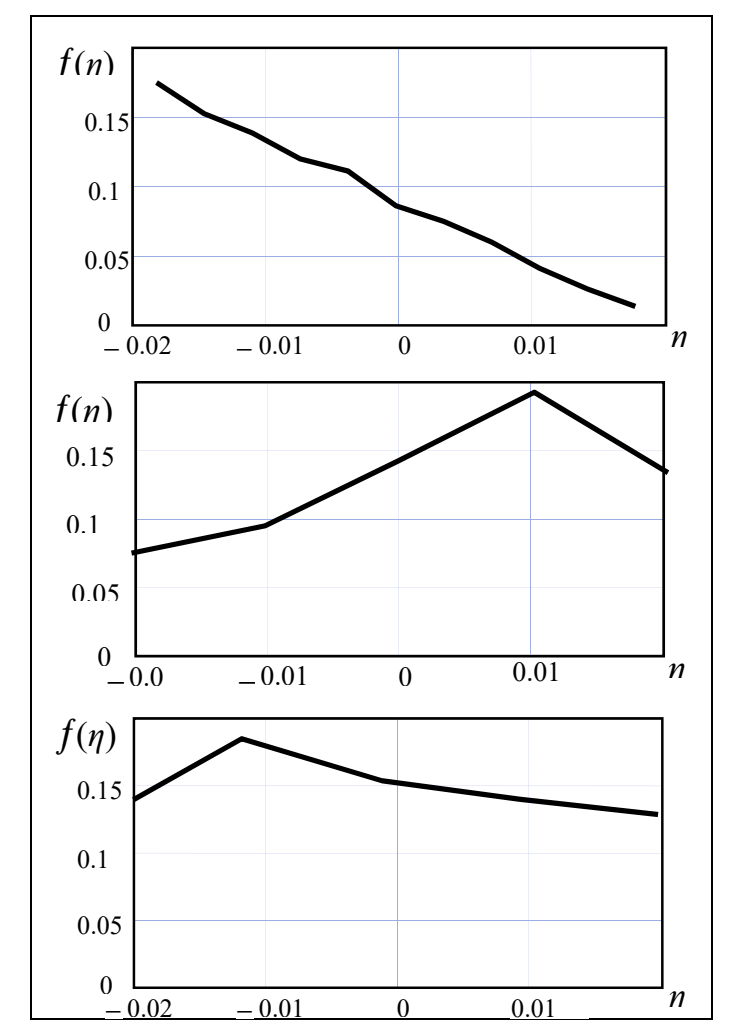

Fig. 6. Function of electron distribution in vicinity of phase velocity of the wave for time moments $\tau=0 ; 3 ; 4$ in single-mode mode. 
The attenuation of the packet leads to the formation of a stable state of the electron velocity distribution function with a practically zero velocity derivative near the phase velocity of the packet (Fig. 7)

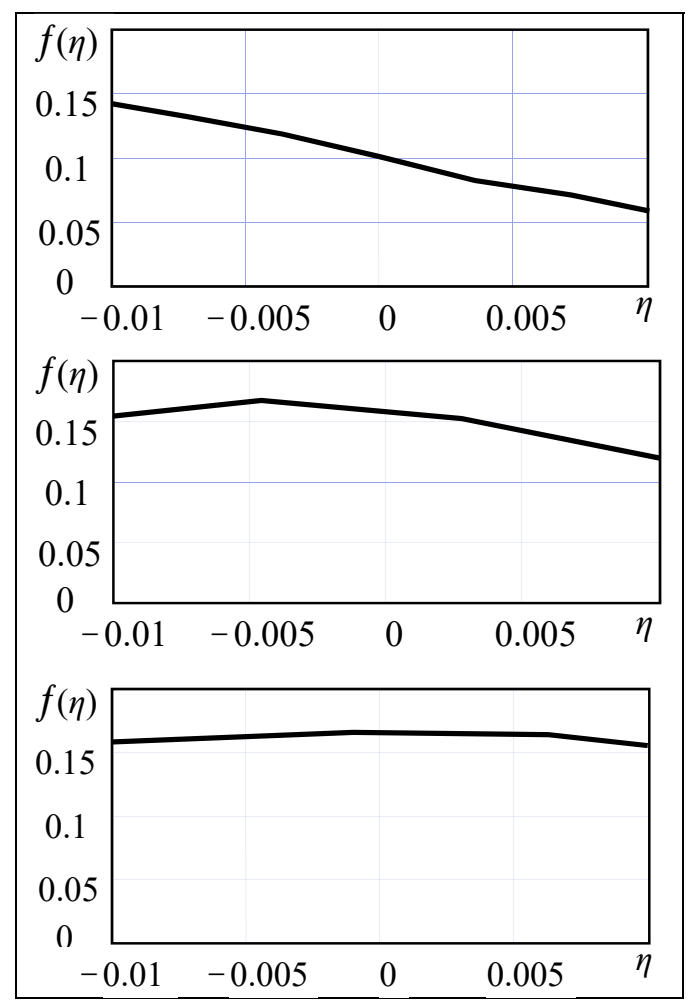

Fig. 7. The function of distribution of electrons in vicinity of phase velocity of the wave for time moments $\tau=0 ; 2 ; 5$ in case of attenuation of the wave packet.

\section{CONCLUSIONS}

When considering the processes of wave attenuation in a resonator filled with an active medium and in a plasma with a finite electron temperature, there is the reason for the transition of the nature of the change in the field amplitude from oscillatory to monotonic with increasing line width of the wave packet.

The nature of the oscillations in a resonator filled with an active medium is associated with the interference of oscillations of the population inversion in local regions. Inversion changes occur with the Rabi frequency, which depends on the electric field of a standing wave formed as a result of reflections from the ends of the resonator. In this case, strong fields or with a significant population inversion, the line width can be neglected. In this case, the field energy density is quite high $|E(t)|^{2} / 4 \pi \gg>\gamma_{12}^{2} \hbar^{2} /\left|d_{a b}\right|^{2}$ (a similar relation can be given for population inversion $\mu>>\gamma_{12}^{2} \cdot \hbar /\left(\omega\left|d_{a b}\right|^{2}\right.$ ). At low levels of electric field intensity or a small population inversion, the inverse inequalities are satisfied and the line width should be taken into account, which leads to suppression of the interference of individual local inversion regions along the waveguide. This mode corresponds to the behavior of the system discussed for the first time in [5]. The nature of the change in the field amplitude becomes monotonic.

In a similar way, the width of the spectrum of the wave packet affects the character of the Landau damping [6] on plasma electrons. In this case, the role of population inversion is played by the quantity $\mu=n_{2}-n_{1}=f\left(v_{0}+\hbar k / m\right)-f\left(v_{0}\right)=(\hbar k / m) \cdot \partial f(v) /\left.\partial v\right|_{v=v_{0}}$, where $f(v)$ is the velocity distribution function of the electrons, $n_{2}, n_{1}$ are the numbers of electrons whose velocity is less than and greater than the phase velocity of the wave.

The role of the Rabi frequency here is played by the oscillation frequency of the trapped particles in the potential well of the field $\Omega_{t r}=\sqrt{e k E / m_{e}}$ (here $e, m_{e}$ the charge and mass of the electron, a $k$ is the wave number of oscillations, and $v_{p h}=\omega / k$ is the phase velocity of the wave).

In the case of a small spectral width of the packet $\Delta k \cdot v_{p h} \approx \Delta \omega<<\Omega_{t r}$, the process of wave attenuation acquires a characteristic oscillatory form associated with the exchange of energy between the wave and plasma electrons captured by its field. In the case of the reverse inequality, the monotonic character of the field attenuation is observed with the formation of a characteristic "plateau" in the vicinity of the phase velocity of the wave on the electron velocity distribution function corresponding to the state with zero population inversion, which is presented in this case as $\mu=(\hbar k / m) \cdot \partial f(v) /\left.\partial v\right|_{v=v_{0}}=0$. 


\section{ACKNOWLEDGMENTS}

The authors are sincerely grateful to V.A. Buts and V.D. Khodusov for useful discussions and attention to the work.

\section{ORCID IDs}

(D) Volodymyr M. Kuklin http://orcid.org/0000-0002-0310-1582, (DEugen V. Poklonskiy https://orcid.org/0000-0001-5682-6694

DSergey M. Sevidov https://orcid.org/0000-0002-9927-9237

\section{REFERENCES}

[1] P.S. Landa Auto-oscillations in distributed systems, (Nauka, Moscow, 1983), pp. 320. (in Russian)

[2] A.S. Davydov Quantum mechanics, (Fizmatgiz, Moscow, 1963), pp. 748. (in Russian)

[3] L. Allen and J. Eberly, Optical resonance and two-level atoms, (Witey-lnterscicitce Publication John Witty and Sons, New YorkLondon-Sydney-Toronto, 1975), pp. 222.

[4] V.M. Kuklin and E.V. Poklonskiy, East Eur. J. Phys. 3, 46-53 (2019), https://doi.org/10.26565/2312-4334-2019-3-06.

[5] A. Einstein, Phys. Zs. 18, 121 (1917), http://web.ihep.su/dbserv/compas/src/einstein17/eng.pdf

[6] L.D. Landau, JETP, 16, 574-586 (1946).

[7] A.A. Rukhadze and V.P. Silin, in: Problems of Theoretical Physics. Scientific works. Issue 2, edited by A.G. Zagorodny, N.F. Shulga and V.M. Kuklin, (KhNU, Kharkiv, 2016), pp. 376. (in Russian)

[8] A.A. Andronov, Izv. Vuz. Radiophysics, 4(5), 861-866 (1961). (in Russian)

[9] A.N .Kondratenko and V.M. Kuklin, Fundamentals of Plasma Electronics, (Energoatomizdat, Moscow, 1988), pp. 320. (in Russian).

[10] A.I. Akhiezer, I.A. Akhiezer, A.G. Sitenko, K.M. Stepanov and R.V. Polovin, Plasma Electrodynamics, (Pergamon, N.Y., 1975), pp. 431.

[11] M.B. Bondarenko, A.N. Kondratenko and V.I. Tkachenko, Izv. Vuz. Radiophysics, 27(11), 962-967 (1984), (in Russian).

[12] E.J. Valeo and C.R. Olerman, Phys. Rev. Lett. 30(21), 1035-1038 (1973), https://doi.org/10.1103/PhysRevLett.30.1035

[13] J.J. Thomson and J.I. Karush, The Physics of Fluids, 17(8), 1608-1613 (1974), https://doi.org/10.1063/1.1694940.

[14] V.M. Kuklin, Selected chapters (theoretical physics), (KhNU, Kharkiv, 2018), pp. 224. (in Russian).

\section{ЗАТУХАНИЕ ВОЛНОВОГО ПАКЕТА В ЗАПОЛНЕННЫХ АКТИВНОЙ СРЕДОЙ И ПЛАЗМОЙ В ОГРАНИЧЕННЫХ СИСТЕМАХ}

В.М. Куклин, Е.В. Поклонский, С.М. Севидов

Харьковский национальный университет имени В. Н. Каразина, Харьков, Украина

пл. Свободы 4, г. Харьков, Украина, 61022

В работе для условий ограниченных систем, которые формируют пространственную структуру поля, рассмотрены процессы затухания волновых пакетов конечной амплитуды. Ширина линии волнового поля определяется как диссипативными процессами (в квантовой системе это величина, обратная времени жизни энергетических уровней) или реактивными процессами (в классических волноводных системах это спектральная ширина пакета). В случае заполнения волновода активной двухуровневой средой описание возможно с помощью квазиклассической модели взаимодействия поля и частиц. При этом квантовомеханическое описание среды объединяется с классическим представлением поля. Здесь существенную роль играет частота Раби, определяющая вероятности индуцированного излучения или поглощения квантов поля и осцилляторное изменение инверсии населенностей (нутацию). В зависимости от соотношения между значениями частоты Раби и ширины линии волнового пакета процесс может менять характер поведения поля. В сильных полях или при значительной инверсии населенностей шириной линии можно пренебречь, при этом плотность энергии поля достаточно велика. В этом случае следует ожидать заметных нутаций инверсии населенностей с разной частотой, отвечающей локальной частоте Раби в разных областях волновода, интерференция которых определит осцилляторное поведение поля волны. При низком уровне интенсивности электрического поля или небольшой инверсии населенностей, режим изменения амплитуды поля становится монотонным. Рассмотрено затухание поля в плазме (затухание Ландау). Роль инверсии населенностей берет на себя величина, пропорциональная производной по скорости от функции распределения электронов. Если спектральная ширина пакета мала, процесс затухания волны приобретает характерный осцилляторный вид, обусловленный обменом энергией между волной и захваченными ее полем электронами плазмы. Затухание широких пакетов практически монотонное с формированием в окрестности фазовой скорости волны характерного «плато» на функции распределения электронов по скоростям.

КЛЮЧЕВЫЕ СЛОВА: затухание волнового пакета, двухуровневая активная среда, интерференция осцилляций инверсии населенностей, затухание Ландау.

\section{ПРО ЗАГАСАННЯ ХВИЛЬОВОГО ПАКЕТУ У ЗАПОВНЕНИХ АКТИВНИМ СЕРЕДОВИЩЕМ ТА ПЛАЗМОЮ У ОБМЕЖЕНИХ СИСТЕМАХ \\ В.М. Куклін, С.В. Поклонський, С.М. Севідов \\ Харківський національний університет імені В.Н. Каразіна, Харків, Украӥна \\ м. Свободи 4, м. Харків, Украӥна, 61022}

В роботі для умов обмежених систем, які формують просторову структуру поля, розглянуті процеси загасання хвильових пакетів кінцевої амплітуди. Ширина лінії хвильового поля визначається як диссипативними процесами (в квантовій системі це величина, зворотна часу життя енергетичних рівнів) або реактивними процесами (в класичних хвилеводних системах це спектральна ширина пакета). У разі заповнення хвилеводу активним дворівневим середовищем опис $є$ можливим за допомогою квазікласичної моделі взаємодії поля і частинок. При цьому квантовомеханічний опис середовища об'єднується 3 класичним уявленням поля. Тут істотну роль грає частота Рабі, що визначає ймовірність індукованого випромінювання або поглинання квантів поля і осциляторну зміну (нутацію) інверсії заселеності. Залежно від співвідношення між значеннями 
частоти Рабі і ширини лінії хвильового пакету може змінюватись характер поведінки поля. У сильних полях або при значній інверсії заселеності шириною лінії можна знехтувати, при цьому щільність енергії поля досить велика. В цьому випадку слід очікувати помітних нутацій інверсії заселеності з різною частотою, що відповідає локальній частоті Рабі в різних областях хвилеводу, інтерференція яких визначить осциляторну поведінку поля хвилі. При низькому рівні інтенсивності електричного поля або невеликий інверсії заселеності, режим зміни амплітуди поля стає монотонним. Розглянуто загасання поля в плазмі (загасання Ландау). Роль інверсії заселеності бере на себе величина, пропорційна похідній по швидкісті від функції розподілу електронів. Якщо спектральна ширина пакета мала, процес загасання хвилі набуває характерного осциляторного вигляду, обумовленого обміном енергією між хвилею і захопленими іiі полем електронами плазми. Загасання широких пакетів практично монотонне 3 формуванням в околиці фазової швидкості хвилі характерного «плато» на функції розподілу електронів за швидкостями.

КЛЮЧОВІ СЛОВА: загасання хвильового пакету, дворівневе активне середовище, інтерференція осциляцій інверсії заселеності, загасання Ландау. 